\title{
Temporal heterogeneity in oxygen tension in human melanoma xenografts
}

\author{
KG Brurberg', BA Graff' and EK Rofstad*,I \\ 'Group of Radiation Biology and Tumor Physiology, Department of Biophysics and Centre for Research and Training in Radiation Therapy, The Norwegian \\ Radium Hospital, Montebello, N-0310 Oslo, Nonway
}

The spatial heterogeneity of the oxygen tension $\left(\mathrm{pO}_{2}\right)$ in human and experimental tumours has been studied extensively, whereas studies of the temporal heterogeneity in $\mathrm{pO}_{2}$ are sparse. In the work reported here, $\mathrm{pO}_{2}$ was measured continuously over periods of at least 60 min in A-07 human melanoma xenografts by using the OxyLite fibre-optic oxygen-sensing device. The main purpose of the work was to establish the usefulness of the OxyLite system in measuring the temporal heterogeneity in $p \mathrm{O}_{2}$ in tissues and to characterise the fluctuations in tissue $\mathrm{pO}_{2}$ in A-07 tumours. The OxyLite device was found to be suitable for studies of the temporal heterogeneity in $\mathrm{pO}_{2}$ in tumours. However, potential pitfalls were identified, and reliable $\mathrm{pO}_{2}$ measurements require that precautions are taken to avoid these pitfalls, that is, erroneous $\mathrm{pO}_{2}$ readings caused by tissue trauma induced by the probe, probe movements induced by reflex actions of the host mouse and occasional probe drift. Significant fluctuations in $\mathrm{pO}_{2}$ were detected in the majority of the 70 tumour regions subjected to measurement. The fluctuations in different regions of the same tumour were in general temporally independent, implying that they were caused primarily by redistribution of the tumour perfusion rather than fluctuations in global perfusion. Fourier analysis of the $\mathrm{pO}_{2}$ traces showed that the $\mathrm{pO}_{2}$ usually fluctuated at frequencies lower than $1.5-2.0 \mathrm{mHz}$, corresponding to less than 0.1 cycle $\mathrm{min}^{-1}$. Haemodynamic effects may cause $\mathrm{pO}_{2}$ fluctuations in this frequency range, and hence, the redistribution of the perfusion could have been caused by morphological abnormalities of the tumour microvasculature. Moreover, acute hypoxia, that is, $\mathrm{pO}_{2}$ fluctuations around 10 or $5 \mathrm{mmHg}$, was detected in 20 of 70 regions, that is, $29 \%$ ( $10 \mathrm{mmHg}$ ), or 27 of 70 regions, that is, $39 \%(5 \mathrm{mmHg})$. The median fraction of the time these regions were acutely hypoxic was $73 \%(10 \mathrm{mmHg})$ or $53 \%$ $(5 \mathrm{mmHg})$. Consequently, if A-07 tumours are adequate models of tumours in man, acute hypoxia may be a commonly occurring phenomenon in neoplastic tissues, and hence, acute hypoxia is likely to cause resistance to radiation therapy and promote tumour aggressiveness.

British Journal of Cancer (2003) 89, 350 - 356. doi:I0.I038/sj.bjc.660I047 www.bjcancer.com

(c) 2003 Cancer Research UK

Keywords: acute hypoxia; oxygen tension; $\mathrm{pO}_{2}$ fluctuations; temporal heterogeneity in $p \mathrm{O}_{2}$

Most tumours are heterogeneous in oxygen tension $\left(\mathrm{pO}_{2}\right)$ and show regions with severely hypoxic cells (Vaupel et al, 1989). Two main types of hypoxia have been recognised: chronic hypoxia, arising from limitations in oxygen diffusion, and acute hypoxia, resulting from transient cessations in microregional blood flow (Horsman, 1995; Brown, 1999). Tumour hypoxia causes resistance to radiation therapy and some forms of chemotherapy (Brown, 1999; Wouters et al, 2002) and promotes malignant progression and the development of metastatic disease (Rofstad, 2000; Höckel and Vaupel, 2001). Clinical investigations have shown that extensive hypoxia in the primary tumour is associated with locoregional treatment failure and poor disease-free and overall survival in several histological types of cancer (Rofstad, 2000; Höckel and Vaupel, 2001; Wouters et al, 2002).

The spatial heterogeneity in $\mathrm{pO}_{2}$ in tumours has been studied in great detail (Vaupel et al, 1989; Vaupel, 1990). Steep gradients in $\mathrm{pO}_{2}$ and $\mathrm{pO}_{2}$ values ranging from $0 \mathrm{mmHg}$ to those found in well-

* Correspondence: Dr EK Rofstad, Department of Biophysics, Institute for Cancer Research, The Norwegian Radium Hospital, Montebello, N-03 IO Oslo, Norway; E-mail: e.k.rofstad@labmed.uio.no Revised I4 March 2003; accepted 27 April 2003 oxygenated normal tissues are characteristic features of tumours, implying that tumour tissues may show extensive spatial heterogeneity in cellular radiation sensitivity (Wouters and Brown, 1997) and hypoxia-induced gene expression (Acker and Plate, 2002; Harris, 2002). In contrast, studies of the temporal heterogeneity in $\mathrm{pO}_{2}$ in tumours are sparse (Dewhirst et al, 2000). However, examinations of fluctuations in microvessel blood flow in window chamber tumours and measurements of the kinetics of red blood cell flux in experimental and human solid tumours by laser Doppler flowmetry have suggested that temporal heterogeneity in $\mathrm{pO}_{2}$ and acute hypoxia are common events in tumour tissues (Endrich et al, 1979; Brizel et al, 1993; Chaplin and Hill, 1995; Hill et al, 1996). Moreover, radiobiological studies of murine tumours and human tumour xenografts have given evidence that acute hypoxia may be a significant cause of tumour radiation resistance (Yamaura and Matsuzawa, 1979; Chaplin et al, 1987; Rofstad and Måseide, 1999). Measurements of temporal heterogeneity in $\mathrm{pO}_{2}$, however, have been reported for tumours of one line only, the rat R3230Ac mammary adenocarcinoma. In these experiments, recessed-tip oxygen microelectrodes (Linsenmeier and Yancey, 1987) were used to record fluctuations in $\mathrm{pO}_{2}$ in tumours implanted subcutaneously (Dewhirst et al, 1998; Braun et al, 1999) or in window chambers (Dewhirst et al, 1996; Kimura et al, 
1996). The studies suggested that tissue $\mathrm{pO}_{2}$ and red blood cell flux fluctuated at low frequencies and were temporally coordinated, and demonstrated that acute hypoxia is a frequently occurring phenomenon in R3230Ac tumours (Dewhirst et al, 1996, 1998; Kimura et al, 1996; Braun et al, 1999).

The low number of investigations of the temporal heterogeneity in $p \mathrm{O}_{2}$ in tumours most likely reflects that adequate equipment for measurement of fluctuations in $\mathrm{pO}_{2}$ in tissues has not been commercially available (Dewhirst et al, 2000). A new oxygensensing device, the OxyLite system, was marketed recently (Young et al, 1996; Griffiths and Robinson, 1999). This device measures $\mathrm{PO}_{2}$ by using a fluorescence quenching technique. Light pulses induce fluorescence in ruthenium chloride incorporated into a silicone rubber polymer at the tip of $220-\mu \mathrm{m}$-diameter fibre-optic probes. The lifetime of the fluorescence is inversely proportional to the oxygen tension at the probe tip. Comparative studies have shown that tumour $\mathrm{pO}_{2}$ distributions and hypoxic fractions measured with the OxyLite system are similar to those obtained with Eppendorf polarographic electrodes (Collingridge et al, 1997; Seddon et al, 2001), recessed-tip microelectrodes (Braun et al, 2001) and radiobiological assays (Urano et al, 2002). The OxyLite system has been used successfully to measure $\mathrm{pO}_{2}$ changes in experimental tumours following different types of physiological intervention (Bussink et al, 2000; Braun et al, 2001;Demeure et al, 2002; Jarm et al, 2002; Jordan et al, 2002).

In the work reported here, the OxyLite system was used to measure $\mathrm{pO}_{2}$ fluctuations in unperturbed A-07 human melanoma xenografts transplanted orthotopically in BALB/c-nu/nu mice. Xenografted A-07 tumours have been shown to retain many biological characteristics of the donor patient's tumour, including cell cycle distribution, angiogenic potential, vascular density, metastatic pattern and several histological and pathophysiological parameters (Rofstad, 1994). The main purpose of the work was to establish the usefulness of the OxyLite system in studying the temporal heterogeneity in $\mathrm{pO}_{2}$ in tissues and to characterise the $p \mathrm{O}_{2}$ fluctuations in a clinically relevant tumour model. Significant evidence was found that the $\mathrm{pO}_{2}$ in many tumour regions fluctuated around the threshold values for hypoxia-induced radiation resistance and hypoxia-induced gene expression.

\section{MATERIALS AND METHODS}

\section{Mice and tumours}

Adult (8-10 weeks of age) female BALB/c-nu/nu mice were used as host animals for xenografted tumours. The mice were maintained under specific pathogen-free conditions at constant temperature $\left(37.0 \pm 0.5^{\circ} \mathrm{C}\right)$ and humidity $(50-60 \%)$. Sterilised food and water were given ad libitum. Experiments were performed with tumours of the A-07 human melanoma line, established as described previously (Rofstad, 1994). Tumours were initiated from exponentially growing cell cultures verified to be free from Mycoplasma contamination. The cells were cultured in RPMI-1640 medium (25 mM HEPES and L-glutamine) supplemented with 13\% bovine calf serum, $250 \mathrm{mgl}^{-1}$ penicillin and $50 \mathrm{mgl}^{-1}$ streptomycin. Approximately $3.5 \times 10^{5}$ cells in $10 \mu \mathrm{l}$ of $\mathrm{Ca}^{2+}$ and $\mathrm{Mg}^{2+}$-free Hanks' balanced salt solution were inoculated intradermally into the hindmost part of the left mouse flank by using a $100-\mu 1$ Hamilton syringe. The tumours were subjected to measurements of $\mathrm{pO}_{2}$ when having volumes within the range of $300-700 \mathrm{~mm}^{3}$. Tumour volume $(V)$ was calculated as $V=(\pi / 6) a b^{2}$, where $a$ is the longer and $b$ is the shorter of two perpendicular diameters, measured with calipers. Animal experiments were approved by the Institutional Committee on Research Animal Care and were performed in accordance with the ethical standards of the UKCCCR 'Guidelines for the Welfare of Animals in Experimental Neoplasia' (Workman et al, 1998).

\section{Measurement of $\mathrm{pO}_{2}$}

Tumour $\mathrm{pO}_{2}$ was measured with a two-channel fibre-optic oxygensensing device (OxyLite ${ }^{\mathrm{TM}}$ 2000, Oxford Optronix, Oxford, UK). The probes were supplied precalibrated by the manufacturer. The calibration data were scanned into a computer by means of a barcode wand. The calibration specification was $\pm 0.7 \mathrm{mmHg}$ or $< \pm 10 \%$ of actual $\mathrm{pO}_{2}$, whichever was greater. To ensure correct $\mathrm{pO}_{2}$ readings, the accuracy of the precalibration data was controlled for every probe by measuring $\mathrm{pO}_{2}$ in Ringers solutions flushed with $\mathrm{N}_{2}$ gas containing $0,0.5,1.0,2.5$ or $5.0 \% \mathrm{O}_{2}$. This procedure was repeated at the end of each experiment to control for drift in the system. Atmospheric pressure was measured with a DPI 705 barometer (Newport Electronics, Deckenpfronn, Germany).

The mice were kept under anaesthesia during the $p \mathrm{O}_{2}$ measurements. A mixture of fentanyl citrate/fluanisone (Janssen Pharmaceutika, Beerse, Belgium) and midazolam (Roche, Basel, Switzerland) was administered intraperitoneally in doses of $0.63 / 20$ and $10 \mathrm{mg} \mathrm{kg}^{-1}$, respectively. The body core temperature of the mice, measured with a rectal probe, was kept at $37.5-38.0^{\circ} \mathrm{C}$ by using a heating lamp and a heating pad. The tumour temperature under these conditions, measured with an OxyLite probe having a fine thermocouple wound around the optic fibre, was within 37.0$38.0^{\circ} \mathrm{C}$, that is, it was similar to the tumour temperature during the growth period prior to the $\mathrm{pO}_{2}$ measurements.

Most tumours had an ellipsoidic shape, and tissue $\mathrm{pO}_{2}$ was measured simultaneously in two positions in each tumour, that is, centrally in each of the two halves of the ellipsoid. The probes were inserted into the tumours through skin punctures made with 21- or 23-gauge needles. After insertion, the probes were retracted by approximately $1 \mathrm{~mm}$ to minimise the pressure on the sensors before they were fixed firmly and $\mathrm{pO}_{2}$ measurements were initiated. The $\mathrm{O}_{2}$ readings were recorded every 5,10 or $30 \mathrm{~s}$ for at least $60 \mathrm{~min}$ and were stored to disc and displayed as time traces by using a data-acquisition system (LabView, National Instruments, Austin, TX, USA). The mice were watched continuously during the experiments and reflex movements were recorded. At the end of the experiments, the mice were killed without withdrawing the probes from the tumour tissue, and it was ensured that the $\mathrm{pO}_{2}$ dropped rapidly to $0 \mathrm{mmHg}$. Data were discarded if (a) changes in tumour $\mathrm{pO}_{2}$ were associated with reflex movements of the host mouse, (b) tumour $\mathrm{pO}_{2}$ did not drop to $0 \mathrm{mmHg}$ after killing of the host mouse or (c) the probe calibration at the end of an experiment gave data that differed significantly from the precalibration data.

\section{Fourier analysis}

Characteristic frequencies of $p \mathrm{O}_{2}$ fluctuations were searched for by subjecting the $\mathrm{pO}_{2}$ traces (oxygen tension $v s$ time) to Fourier analysis. The Fourier analysis was performed by using IDL software (Research Systems, Boulder, CO, USA). The program calculated frequency spectra from $\mathrm{pO}_{2}$ traces by accomplishing a discrete Fourier transformation. The highest detectable frequency was given by the sampling frequency and was $100 \mathrm{mHz}$ at a sampling frequency of $5 \mathrm{~s}$. The lowest detectable frequency was given by the length of the observation period and was approximately $0.4 \mathrm{mHz}$ at an observation period of $40 \mathrm{~min}$.

\section{RESULTS}

Measurement of $\mathrm{pO}_{2}$ in A-07 tumours with OxyLite probes gave values that varied substantially with time. The variations were more pronounced shortly after the probe insertion than towards the end of the observation period. Two characteristic $p \mathrm{O}_{2}$ traces are illustrated in Figure 1A. The initial $p \mathrm{O}_{2}$ was above $5 \mathrm{mmHg}$ in both traces. In trace $\# 1$, the $p \mathrm{O}_{2}$ decreased for several minutes 
before it increased gradually and reached a high and fairly stable level. In trace $\# 2$, the $p \mathrm{O}_{2}$ decreased rapidly with time before a low and fairly stable level was reached. To investigate whether the initial changes in $p \mathrm{O}_{2}$ were artefacts caused by the probe insertion, similar $\mathrm{pO}_{2}$ measurements were performed in muscle tissue in BALB/c- $n u / n u$ mice. Two typical $p \mathrm{O}_{2}$ traces from muscle tissue are presented in Figure $1 \mathrm{~B}$. The muscle $\mathrm{pO}_{2}$ traces were qualitatively similar to $p \mathrm{O}_{2}$ trace \#1 in Figure $1 \mathrm{~A}$, strongly suggesting that the initial $\mathrm{pO}_{2}$ changes were artefacts.

To determine the length of the time period in which the $\mathrm{pO}_{2}$ readings in A-07 tumours obviously were influenced by the probe insertion, 50 randomly selected $p^{2}$ traces were normalised and summed. The normalisation was performed by dividing all $p \mathrm{O}_{2}$ values in a trace by the highest $p \mathrm{O}_{2}$ value recorded in that trace, excluding $\mathrm{pO}_{2}$ values recorded during the first $10 \mathrm{~min}$ when determining the normalisation factor. The $p \mathrm{O}_{2}$ trace representing the sum of the normalised $p \mathrm{O}_{2}$ traces is plotted in Figure 2. This plot suggests that the changes in $p_{2}$ recorded within the first $20 \mathrm{~min}$ after the probe insertion were systematic and hence were artefacts caused by the probe, whereas the $\mathrm{pO}_{2}$ changes recorded beyond $20 \mathrm{~min}$ were random and hence most likely represented true variations in tissue $\mathrm{pO}_{2}$. Consequently, the temporal heterogeneity in $\mathrm{pO}_{2}$ in A-07 tumours was studied by only considering $p \mathrm{O}_{2}$ values recorded beyond the first 20 min after the insertion of a probe, that is, the first 20 min of each $\mathrm{pO}_{2}$ trace was excluded in the analysis presented below.

A total of 38 A-07 tumours were subjected to $p \mathrm{O}_{2}$ measurements and a total of 70 reliable $p \mathrm{O}_{2}$ traces were obtained. The $p \mathrm{O}_{2}$ traces
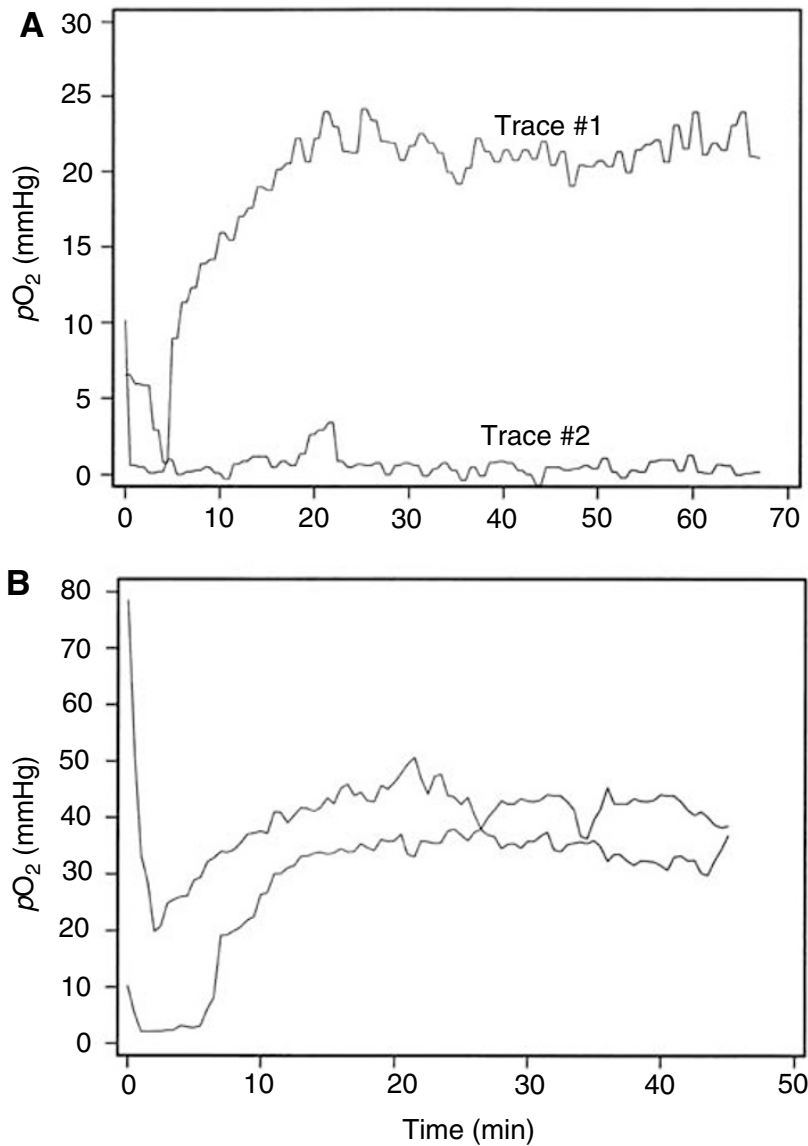

Figure I Examples of $\mathrm{pO}_{2}$ traces recorded with OxyLite probes in A-07 tumours $(\mathbf{A})$ and muscle tissue $(\mathbf{B})$. The traces show that the changes in $\mathrm{pO}_{2}$ were more pronounced shortly after the probe insertion than towards the end of the observation period.

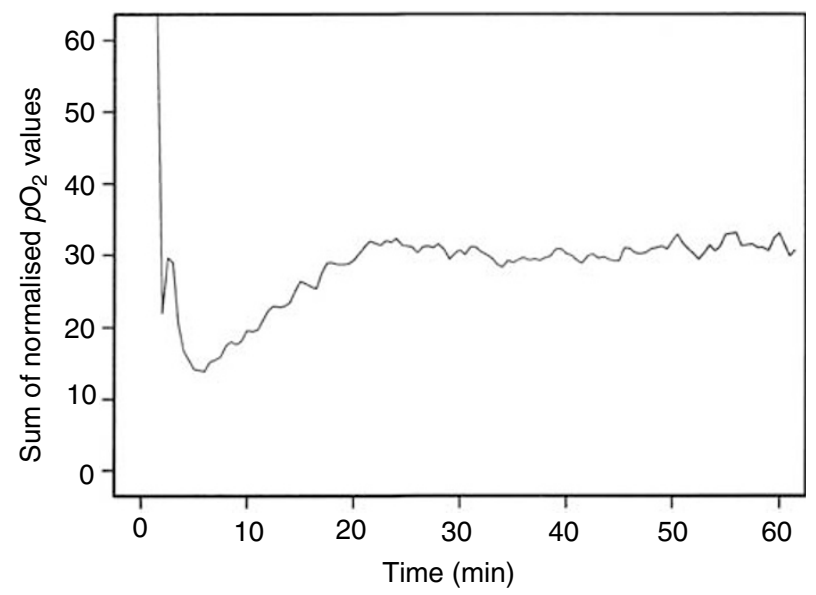

Figure 2 Sum of 50 normalised $\mathrm{pO}_{2}$ traces recorded with OxyLite probes in A-07 tumours. The composed trace shows that the changes in $\mathrm{pO}_{2}$ recorded within the first $20 \mathrm{~min}$ after the probe insertion were systematic, whereas those recorded beyond the first 20 min were random.

showed substantial differences, regardless of whether they were recorded in the same tumour or in different tumours. Mean $\mathrm{pO}_{2}$ differed among the traces from 0 to $38 \mathrm{mmHg}$. Examples of characteristic $\mathrm{pO}_{2}$ traces are illustrated in Figure 3. Both welloxygenated and poorly oxygenated tumour regions could show $\mathrm{pO}_{2}$ traces without significant fluctuations (Figure $3 \mathrm{~A}$ ). However, significant $\mathrm{pO}_{2}$ fluctuations were detected in most tumour regions (Figure $3 \mathrm{~B}$ ). The $\mathrm{pO}_{2}$ traces were analysed by using two threshold values for hypoxia, that is, $\mathrm{OO}_{2}=5$ and $10 \mathrm{mmHg}$. Some tumour regions were not hypoxic at all during the observation period, whereas others were hypoxic during the entire period (Table 1). Acute hypoxia, that is, $p \mathrm{O}_{2}$ fluctuations around the threshold values, was detected in $29 \%(10 \mathrm{mmHg})$ and $39 \%(5 \mathrm{mmHg})$ of the tumour regions. To characterise the kinetics of the acute hypoxia, the number of times per hour the $\mathrm{pO}_{2}$ decreased below the threshold values and the fractional time the $\mathrm{pO}_{2}$ was below the threshold values were calculated for each of the tumour regions showing acute hypoxia. The durations of the hypoxic periods were also determined. The median values and the ranges of these parameters are presented in Table 1. A similar analysis has been performed previously for R3230Ac rat tumours (Dewhirst et al, 1998), and the results of this analysis were included in Table 1 for comparison.

Two $p \mathrm{O}_{2}$ traces were recorded simultaneously in most tumours. None of the traces, one of the traces, or both traces could show significant $p \mathrm{O}_{2}$ fluctuations. The $p \mathrm{O}_{2}$ values of concurrent traces were subjected to correlation analysis to investigate whether the $p \mathrm{O}_{2}$ fluctuations in different regions of the same tumour were temporally coordinated. Positive correlations were found in some tumours (Figure 4A), whereas inverse correlations were seen in others (Figure 4B). However, there was no correlation between the two series of $p \mathrm{O}_{2}$ values in the majority of the tumours, implying that the $\mathrm{pO}_{2}$ fluctuations in different regions of a tumour in general were temporally independent.

Moreover, the $\mathrm{pO}_{2}$ traces were subjected to Fourier analysis to investigate whether the $\mathrm{pO}_{2}$ fluctuated at characteristic frequencies. The Fourier analysis resulted in frequency spectra that were not qualitatively different, regardless of whether they were derived from the same tumour or from different tumours. The frequency spectra indicated that the $p \mathrm{O}_{2}$ fluctuated at very low frequencies, that is, at frequencies lower than $1.5-2.0 \mathrm{mHz}$, corresponding to less than 0.1 cycle $\mathrm{min}^{-1}$. Significant fluctuations at higher frequencies could not be detected. Data from a characteristic tumour region are presented in Figure 5, showing the $\mathrm{pO}_{2}$ trace 

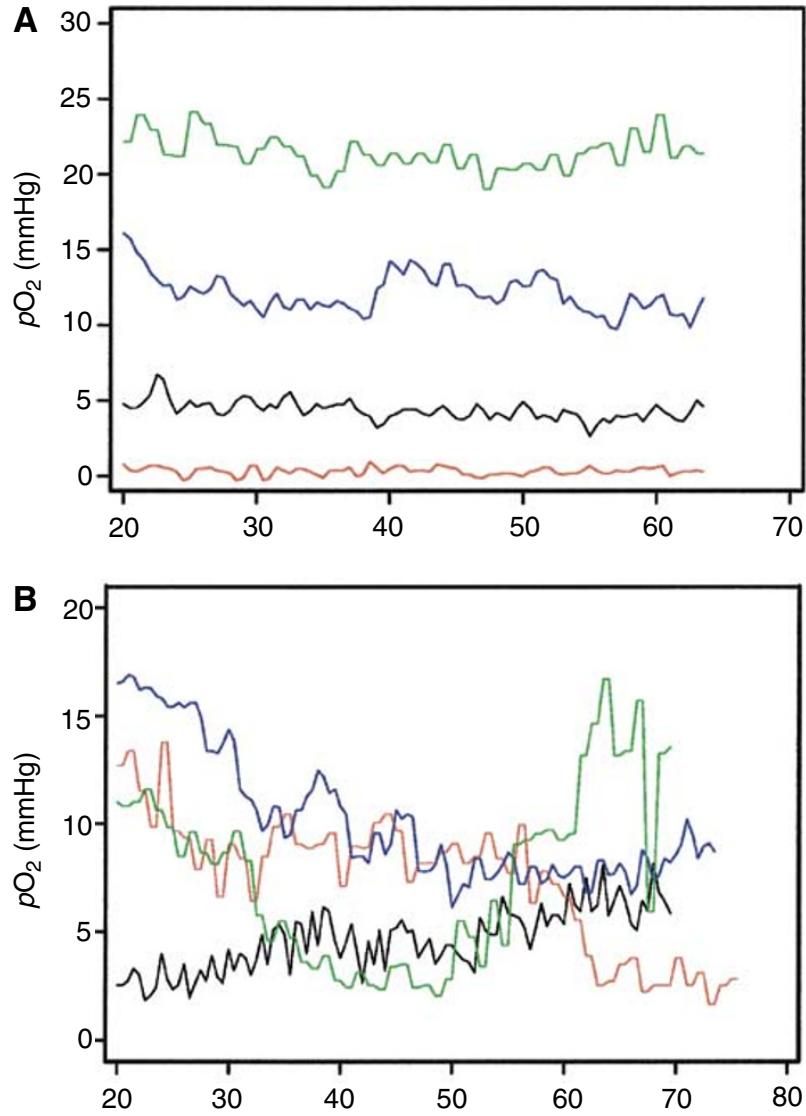

Figure 3 Examples of $\mathrm{pO}_{2}$ traces recorded with $\mathrm{OxyLite}$ probes in $\mathrm{A}-07$ tumours. The traces refer to tumour regions without significant fluctuations in $\mathrm{pO}_{2}(\mathbf{A})$ and tumour regions showing significant fluctuations in $\mathrm{pO}_{2}$ around $\mathrm{pO}_{2}$ values of 5 and $10 \mathrm{mmHg}(\mathbf{B})$

(Figure 5A) and the corresponding frequency spectrum (Figure 5B).

\section{DISCUSSION}

Tissue $\mathrm{pO}_{2}$ in A-07 human melanoma xenografts was monitored continuously over periods of at least $60 \mathrm{~min}$ by using OxyLite fibre-optic probes. The study showed that fluctuations in $p \mathrm{O}_{2}$ at the microregional level occur frequently in A-07 tumours. Moreover, acute hypoxia was found to be a common phenomenon in these tumours, which is in agreement with the conclusions from a previous study in which radiobiological and immunohistochemical assays were used to detect hypoxia in A-07 and other human melanoma xenografts (Rofstad and Måseide, 1999). The OxyLite system has been used previously to study changes in tumour $\mathrm{pO}_{2}$ following treatment with blood flow and tissue oxygenation modifying agents (Bussink et al, 2000; Braun et al, 2001;Demeure et al, 2002; Jarm et al, 2002; Jordan et al, 2002). The present study is the first in which the OxyLite system has been used successfully to study temporal heterogeneity in $p \mathrm{O}_{2}$ in unperturbed tumours.

Studies of temporal heterogeneity in $\mathrm{pO}_{2}$ in tumour tissue with the OxyLite system, however, require precautions against potential methodical pitfalls, as revealed by the work reported here. First, it was observed that the $\mathrm{pO}_{2}$ values recorded shortly after the probe was inserted into tumour tissue varied systematically with time and hence were influenced signifcantly by the probe insertion. A similar artefact was seen when tissue $\mathrm{pO}_{2}$ was measured in P22 rat carcinosarcomas with OxyLite probes (Seddon et al, 2001). The $\mathrm{pO}_{2}$ readings stabilised after approximately $10 \mathrm{~min}$ in $\mathrm{P} 22$ tumours, whereas in A-07 tumours, reliable $\mathrm{pO}_{2}$ readings could not be obtained until $20 \mathrm{~min}$ after the probe insertion. The artificial $p \mathrm{O}_{2}$ readings obtained during the first 20 min of measurement in A-07 tumours were most likely a result of vasoconstrictive reactions to tissue trauma induced by the probe. However, other factors may also have contributed, as discussed in detail for P22 tumours (Seddon et al, 2001). Second, it was observed that abrupt changes in the $\mathrm{pO}_{2}$ readings could occur simultaneously with reflex movements of the host mouse. These changes did probably not reflect temporal heterogeneity in $p \mathrm{O}_{2}$, but were rather a consequence of minor changes in probe position and hence the spatial heterogeneity in $p \mathrm{O}_{2}$, as it is well known that tumour tissues can show steep $\mathrm{pO}_{2}$ gradients (Vaupel, 1990; Horsman, 1995; Braun et al, 2001; Urano et al, 2002). Third, it was observed that some correctly precalibrated probes after a few measurements in tissue suddenly began recording erroneous absolute values of $p \mathrm{O}_{2}$. Therefore, it is essential to kill the host animals after each experiment and ensure that the $p \mathrm{O}_{2}$ drops rapidly to $0 \mathrm{mmHg}$, and to control the probe calibration regularly in Ringers solutions, as was followed in the work reported here.

Our analysis was based on the assumption that the $\mathrm{pO}_{2}$ readings recorded beyond the first $20 \mathrm{~min}$ after the probe insertion were not influenced significantly by the tissue trauma caused by the probe. The OxyLite probes have a tip diameter of $220 \mu \mathrm{m}$ and may therefore now and then cause severe tissue damage during the insertion, for example by destroying or compressing larger vessels. Consequently, it cannot be excluded that the $\mathrm{pO}_{2}$ readings in some of the tumour regions studied here were influenced by probeinduced tissue damage also beyond the first $20 \mathrm{~min}$. However, several observations suggest that this potential problem, if present, was of minor significance. First, $p \mathrm{O}_{2}$ was measured in normal tissues also, and significant $\mathrm{pO}_{2}$ fluctuations were never observed beyond $20 \mathrm{~min}$, as illustrated for muscle tissue in Figure $1 \mathrm{~B}$. Second, we have shown that the mean $\mathrm{pO}_{2}$ measured beyond $20 \mathrm{~min}$ is inversely correlated to the fraction of radiobiologically hypoxic cells in A-07 and R-18 human melanoma xenografts (Brurberg et al, unpublished data). Moreover, comparative studies performed in other laboratories have demonstrated that the $\mathrm{pO}_{2}$ distributions measured in experimental tumours with OxyLite

Table I Parameters describing the kinetics of acute hypoxia in A-07 human melanoma xenografts and R3230Ac rat mammary adenocarcinomas

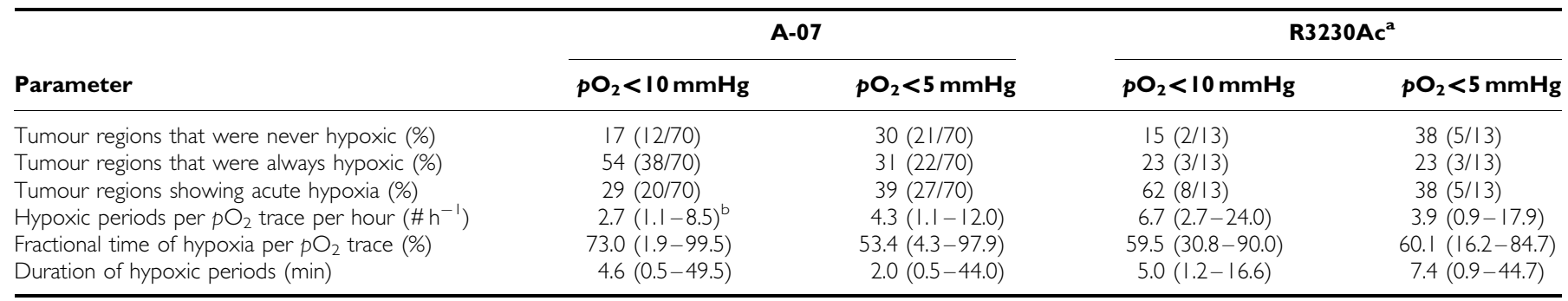

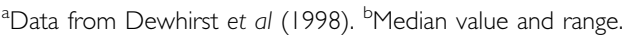



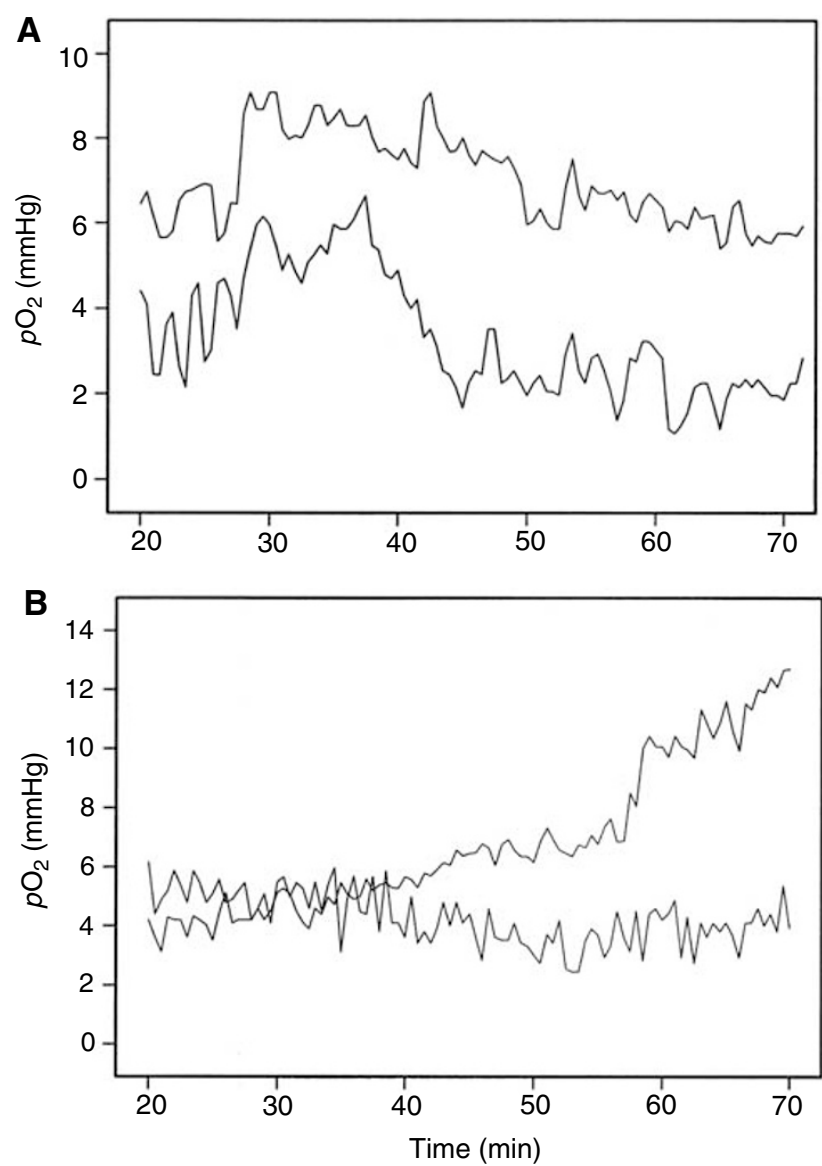

Figure 4 Examples of $\mathrm{pO}_{2}$ traces recorded simultaneously with OxyLite probes in two regions of the same A-07 tumours. The traces refer to a tumour where the $\mathrm{pO}_{2}$ values were correlated $(\mathbf{A})$ and a tumour where the $\mathrm{pO}_{2}$ values were inversely correlated $(\mathbf{B})$.

probes are similar to those obtained with Eppendorf polarographic electrodes (Collingridge et al, 1997; Seddon et al, 2001) and recessed-tip microelectrodes (Braun et al, 2001).

Previous studies of the rat R3230Ac mammary adenocarcinoma have led to the suggestion that fluctuations in tissue $\mathrm{pO}_{2}$ and acute hypoxia may be commonly occurring phenomena in tumours (Dewhirst et al, 1996, 1998; Kimura et al, 1996; Braun et al, 1999). The present study of A-07 human melanoma xenografts, which have been shown to retain several characteristic biological features of the donor patient's tumour (Rofstad, 1994) and hence most likely are more relevant models of tumours in man than are R3230Ac tumours, confirmed this suggestion. A direct comparison of the temporal heterogeneity in $\mathrm{pO}_{2}$ in A-07 and R3230Ac tumours is difficult, however, because OxyLite fibre-optic probes were used to measure $\mathrm{pO}_{2}$ in the present work and recessed-tip microelectrodes were used to measure $p_{2}$ in the R3230Ac tumours. The tip diameter of the OxyLite probes is $220 \mu \mathrm{m}$, and the sampling volume has been estimated to be approximately 1000 cells (Griffiths and Robinson, 1999; Seddon et al, 2001). In contrast, the recessed-tip microelectrodes had a diameter of only 10-12 $\mu \mathrm{m}$ (Dewhirst et al, 1998), and therefore, they had a sampling volume that was substantially smaller than that of the OxyLite probes (Braun et al, 2001). Since tumours are spatially heterogeneous in $\mathrm{pO}_{2}$ at the microregional level (Vaupel, 1990; Horsman, 1995), microelectrodes are expected to measure larger fluctuations in $\mathrm{pO}_{2}$ in tumours than are OxyLite probes (Braun et al, 2001). Nevertheless, the temporal heterogeneity in $\mathrm{pO}_{2}$ measured in A-07 tumours was remarkably similar to that
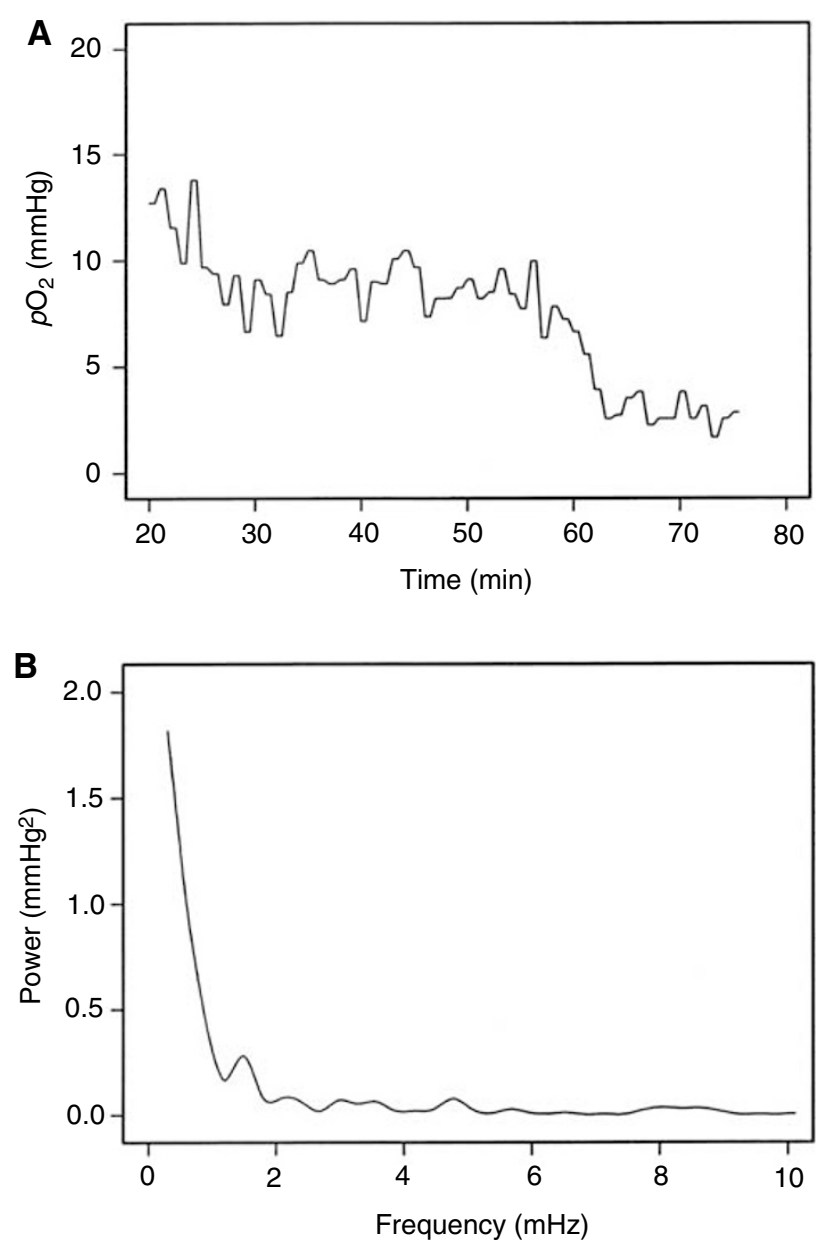

Figure 5 Example of a $\mathrm{pO}_{2}$ trace recorded with an OxyLite probe in an A-07 tumour $(\mathbf{A})$ and the corresponding frequency spectrum (B). The frequency spectrum, which was obtained by subjecting the $\mathrm{pO}_{2}$ data to Fourier analysis, suggests that the $\mathrm{pO}_{2}$ fluctuated at frequencies lower than $1.5-2.0 \mathrm{mHz}$.

measured in R3230Ac tumours, as can be seen from the comparison of A-07 and R3230Ac tumours presented in Table 1.

Temporal heterogeneity in $\mathrm{pO}_{2}$ in tumour tissue has to be caused by temporal heterogeneity in either oxygen delivery, that is, blood supply, or oxygen consumption, that is, cell respiration, or both. There is no experimental evidence that the rate of respiration may fluctuate synchronously in cells within tumour microregions. On the other hand, there is ample evidence that the blood supply may fluctuate significantly at the microregional level in both experimental and human tumours (Endrich et al, 1979; Brizel et al, 1993; Chaplin and Hill, 1995; Hill et al, 1996). Studies of R3230Ac tumours transplanted to window chambers have suggested that the fluctuations in $p \mathrm{O}_{2}$ in these tumours were temporally coordinated with fluctuations in red blood cell flux (Dewhirst et al, 1996; Kimura et al, 1996). Moreover, Fourier analysis of $\mathrm{pO}_{2}$ traces recorded with recessed-tip microelectrodes and red blood cell flux traces recorded by laser Doppler flowmetry revealed that both $\mathrm{pO}_{2}$ and blood flow fluctuated at very low frequencies in subcutaneous R3230Ac tumours (Braun et al, 1999). The data reported here for A-07 tumours are in good agreement with those of the R3230Ac tumours. Thus, the $p \mathrm{O}_{2}$ frequency spectra of the A-07 tumours suggested that the $\mathrm{pO}_{2}$ fluctuated at low frequencies also in these tumours, that is, at frequencies lower than $1.5-2.0 \mathrm{mHz}$, corresponding to less than 0.1 cycle $\min ^{-1}$. Fluctuations in $\mathrm{pO}_{2}$ in this frequency range could result from fluctuations in blood flow 
caused by vasomotion in supplying arterioles, haemodynamic mechnisms and/or microvascular remodelling via intussusceptive vascular growth (Braun et al, 1999). Haemodynamic mechanisms may be particularly significant because the blood viscosity is elevated in tumour tissues and the tumour microvascular network is irregular and chaotic (Vaupel et al, 1989).

Studies of intratumour heterogeneity in temporal variation in $p \mathrm{O}_{2}$ have not been reported so far. The $p \mathrm{O}_{2}$ measurements performed in R3230Ac tumours were all restricted to a single point at a time in each tumour (Dewhirst et al, 1996, 1998; Kimura et al, 1996; Braun et al, 1999). Therefore, these studies did not provide information on the fractional tumour volume showing $p_{2}$ fluctuations or on the temporal coordination of the $\mathrm{pO}_{2}$ fluctuations in different tumour regions. Attempts to obtain information of this type were made in the present work by measuring $\mathrm{pO}_{2}$ simultaneously in two distinctly different regions of the same A-07 tumours. In some tumours, significant fluctuations in $p \mathrm{O}_{2}$ could not be detected in any of the regions, and in others, $p \mathrm{O}_{2}$ fluctuated significantly in one of the regions only, suggesting that the $\mathrm{pO}_{2}$ fluctuations usually involved only a fraction of the tumour volume. Many A-07 tumours, however, showed significant $p \mathrm{O}_{2}$ fluctuations in both regions. These fluctuations were in general not temporally coordinated, suggesting that they were caused primarily by redistribution of the perfusion within the tumours rather than changes in global perfusion. Thus, in some tumours, the $\mathrm{pO}_{2}$ values in the two regions analysed simultaneously were inversely correlated. However, our experiments can by no means exclude the possibility that also the global perfusion and hence the fraction of acutely hypoxic cells varied significantly with time. In fact, this possibility is very likely, considering the irregular and heterogeneous nature of the microvasculature of tumours, and is supported by the observation that the two $p \mathrm{O}_{2}$ series recorded simultaneously were strongly correlated in some tumours. Studies of temporal heterogeneity in $\mathrm{pO}_{2}$ involving mapping of the $\mathrm{pO}_{2}$ distribution in whole tumours are needed, however, before this question can be settled.

The study reported here may have significant implications for the radiation therapy of cancer. First, clinical studies attempting to eliminate the chronic hypoxia in tumours during radiation therapy are being performed, but so far, the therapeutic results have been unsatisfactory (Overgaard and Horsman, 1996). The present observations suggest that a significant fraction of the hypoxic cells in tumours are acutely hypoxic, and acutely hypoxic cells may be more resistant to radiation therapy than chronically hypoxic cells (Pettersen and Wang, 1996; Zölzer and Streffer, 2002). Consequently, treatment strategies aiming at reducing the fraction of acutely hypoxic cells may prove more successful in improving the outcome of radiation therapy than those aiming at reducing the fraction of chronically hypoxic cells. Second, serious attempts have been initiated to improve the local control of radiation-resistant tumours by using intensity modulated radiation therapy for selective boosting of hypoxic subvolumes (Tome and Fowler, 2000; Chao et al, 2001; Popple et al, 2002). Our observations suggest that the spatial distribution of the acutely hypoxic regions in tumours may change rapidly with time. Consequently, efficient selective boosting of hypoxic subvolumes may require novel technology for imaging of tumour hypoxia and guiding of intensity-modulated radiation therapy.

The present observations are also relevant for our understanding of the malignant progression of tumours and the development of metastatic disease. It is well established that tumour hypoxia activates DNA transcription factors, for example, HIF-1, and leads to increased expression of a large number of genes, and a high expression of these genes has been shown to be associated with poor prognosis in several histological types of cancer (Rofstad, 2000; Höckel and Vaupel, 2001; Acker and Plate, 2002; Harris, 2002; Wouters et al, 2002). Some of the genes that are activated under hypoxic conditions encode proteins involved in the metastatic process, for example, angiogenesis factors and proteolytic enzymes. Studies of human melanoma xenografts have shown that tumour hypoxia may promote metastasis by upregulating the expression of interleukin- 8 (Rofstad and Halsør, 2002) and urokinase-type plasminogen activator receptor (Rofstad et al, 2002). The study reported here showed that a significant fraction of the hypoxic volume of tumours may be acutely hypoxic and that the spatial distribution of the acutely hypoxic regions may change rapidly with time. It is possible that the dynamic nature of the acute hypoxia in tumours may lead to hypoxia-induced gene expression without loss of viability in a substantial fraction of the malignant cells and hence may promote aggressiveness and metastatic spread. Consistent with this suggestion is the observation that experimentally imposed acute hypoxia but not chronic hypoxia-enhanced spontaneous metastasis in KHT murine tumours (Cairns et al, 2001).

In summary, the present study showed that significant fluctuations in tissue $\mathrm{pO}_{2}$ and acute hypoxia are commonly occurring phenomena in A-07 human melanoma xenografts. If A07 tumours are relevant models of tumours in man, acute hypoxia may be an important cause of resistance to radiation therapy and malignant progression in human cancer.

\section{ACKNOWLEDGEMENTS}

Berit Mathiesen and Kristil Kindem are thanked for skilful technical assistance. Financial support was received from The Norwegian Cancer Society.

\section{REFERENCES}

Acker T, Plate KH (2002) A role for hypoxia and hypoxia-inducible transcription factors in tumor physiology. J Mol Med 80: 562-575

Braun RD, Lanzen JL, Dewhirst MW (1999) Fourier analysis of fluctuations of oxygen tension and blood flow in R3230Ac tumors and muscle in rats. Am J Physiol 277: H551 - H568

Braun RD, Lanzen JL, Snyder SA, Dewhirst MW (2001) Comparison of tumor and normal tissue oxygen tension measurements using OxyLite or microelectrodes in rodents. Am J Physiol 280: $\mathrm{H} 2533$ - $\mathrm{H} 2544$

Brizel DM, Klitzman B, Cook JM, Edwards J, Rosner G, Dewhirst MW (1993) A comparison of tumor and normal tissue microvascular hematocrits and red cell fluxes in a rat window chamber model. Int $J$ Radiat Oncol Biol Phys 25: 269-276

Brown JM (1999) The hypoxic cell: a target for selective cancer therapy eighteenth Bruce F. Cain memorial award lecture. Cancer Res 59: $5863-5870$
Bussink J, Kaanders JHAM, Strik AM, van der Kogel AJ (2000) Effects of nicotinamide and carbogen on oxygenation in human tumor xenografts measured with luminescence based fiber-optic probes. Radiother Oncol 57: $21-30$

Cairns RA, Kalliomaki T, Hill RP (2001) Acute (cyclic) hypoxia enhances spontaneous metastasis of KHT murine tumors. Cancer Res 61: $8903-8908$

Chao KS, Bosch WR, Mutic S, Lewis JS, Dehdashti F, Mintun MA, Dempsey JF, Perez CA, Purdy JA, Welch MJ (2001) A novel approach to overcome hypoxic tumor resistance: $\mathrm{Cu}$-ATSM-guided intensitymodulated radiation therapy. Int J Radiat Oncol Biol Phys 49: $1171-1182$

Chaplin DJ, Hill SA (1995) Temporal heterogeneity in microregional erythrocyte flux in experimental solid tumours. Br J Cancer 71: 12101213 
Chaplin DJ, Olive PL, Durand RE (1987) Intermittent blood flow in a murine tumor: radiobiological effects. Cancer Res 47: 597-603

Collingridge DR, Young WK, Vojnovic B, Wardman P, Lynch EM, Hill SA, Chaplin DJ (1997) Measurement of tumor oxygenation: a comparison between polarographic needle electrodes and a time-resolved luminescence-based optical sensor. Radiat Res 147: 329-334

Demeure RJ, Jordan BF, Yang QX, Beghein N, Smith MB, Gregoire B, Gallez B (2002) Removal of local field gradient artefacts in BOLD contrast imaging of head and neck tumours. Phys Med Biol 47: $1819-1825$

Dewhirst MW, Braun RD, Lanzen JL (1998) Temporal changes in $p \mathrm{O}_{2}$ of R3230Ac tumors in Fischer-334 rats. Int J Radiat Oncol Biol Phys 42: $723-726$

Dewhirst MW, Kimura H, Rehmus SWE, Braun RD, Papahadjopoulos D, Hong K, Secomb TW (1996) Microvascular studies on the origins of perfusion-limited hypoxia. Br J Cancer 74(Suppl XXVII): S247 - S251

Dewhirst MW, Klitzman B, Braun RD, Brizel DM, Haroon ZA, Secomb TW (2000) Review of methods used to study oxygen transport at the microcirculatory level. Int J Cancer Radiat Oncol Invest 90: $237-255$

Endrich B, Intaglietta M, Reinhold HS, Gross JF (1979) Hemodynamic characteristics in microcirculatory blood channels during early tumor growth. Cancer Res 39: 17-23

Griffiths JR, Robinson P (1999) The OxyLite: a fibre-optic oxygen sensor. $\mathrm{Br}$ J Radiol 72: $627-630$

Harris AL (2002) Hypoxia - a key regulatory factor in tumour growth. Nat Rev Cancer 2: $38-47$

Hill SA, Pigott KH, Saunders MI, Powell MEB, Arnold S, Obeid A, Ward G, Leahy M, Hoskin PJ, Chaplin DJ (1996) Microregional blood flow in murine and human tumours assessed using laser Doppler microprobes. Br J Cancer 74(Suppl XXVII): S260-S263

Horsman MR (1995) Nicotinamide and other benzamide analogs as agents for overcoming hypoxic cell radiation resistance in tumours. Acta Onco 34: $571-587$

Höckel M, Vaupel P (2001) Tumor hypoxia: definitions and current clinical, biologic, and molecular aspects. J Natl Cancer Inst 93: $266-276$

Jarm T, Sersa G, Miklavcic D (2002) Oxygenation and blood flow in tumors treated with hydralazine: evaluation with a novel luminescence-based fiber-optic sensor. Technol Health Care 10: 363-380

Jordan BF, Grégoire V, Demeure RJ, Sonveaux P, Feron O, O'Hara J, Vanhulle VP, Delzenne N, Gallez B (2002) Insulin increases the sensitivity of tumors to irradiation: involvement of an increase in tumor oxygenation mediated by a nitric oxide-dependent decrease of the tumor cells oxygen consumption. Cancer Res 62: 3555-3561

Kimura H, Braun RD, Ong ET, Hsu R, Secomb TW, Papahadjopoulos D, Hong K, Dewhirst MW (1996) Fluctuations in red cell flux in tumo microvessels can lead to transient hypoxia and reoxygenation in tumor parenchyma. Cancer Res 56: $5522-5528$

Linsenmeier RA, Yancey CM (1987) Improved fabrication of doublebarreled recessed cathode oxygen microelectrodes. J Appl Physiol 63: $2554-2557$

Overgaard J, Horsman MR (1996) Modification of hypoxia-induced radioresistance in tumors by the use of oxygen and sensitizers. Semin Radiat Oncol 6: $10-21$
Pettersen EO, Wang H (1996) Radiation-modifying effect of oxygen in synchronized cells pre-treated with acute or prolonged hypoxia. Int $J$ Radiat Biol 70: 319-326

Popple RA, Ove R, Shen S (2002) Tumor control probability for selective boosting of hypoxic subvolumes, including the effect of reoxygenation. Int J Radiat Oncol Biol Phys 54: 921 - 927

Rofstad EK (1994) Orthotopic human melanoma xenograft model systems for studies of tumour angiogenesis, pathophysiology, treatment sensitivity and metastatic pattern. Br J Cancer 70: 804-812

Rofstad EK (2000) Microenvironment-induced cancer metastasis. Int $J$ Radiat Biol 76: 589-605

Rofstad EK, Hals $ø$ r EF (2002) Hypoxia-associated spontaneous pulmonary metastasis in human melanoma xenografts: involvement of microvascular hot spots induced in hypoxic foci by interleukin 8 . Br J Cancer 86: $301-308$

Rofstad EK, Måseide K (1999) Radiobiological and immunohistochemical assessment of hypoxia in human melanoma xenografts: acute and chronic hypoxia in individual tumours. Int J Radiat Biol 75: 1377-1393

Rofstad EK, Rasmussen H, Galappathi K, Mathiesen B, Nilsen K, Graff BA (2002) Hypoxia promotes lymph node metastasis in human melanoma xenografts by up-regulating the urokinase-type plasminogen activator receptor. Cancer Res 62: $1847-1853$

Seddon BM, Honess DJ, Vojnovic B, Tozer GM, Workman P (2001) Measurement of tumor oxygenation: in vivo comparison of a luminescence fiber-optic sensor and a polarographic electrode in the P22 tumor. Radiat Res 155: 837-846

Tome WA, Fowler JF (2000) Selective boosting of tumor subvolumes. Int $J$ Radiat Oncol Biol Phys 48: 593-599

Urano M, Chen Y, Humm J, Koutcher JA, Zanzonico P, Ling C (2002) Measurements of tumor tissue oxygen tension using a time-resolved luminescence-based optical OxyLite probe: comparison with a paired survival assay. Radiat Res 158: $167-173$

Vaupel P (1990) Oxygenation of human tumors. Strahlenther Onkol 166: $377-386$

Vaupel P, Kallinowski F, Okunieff P (1989) Blood flow, oxygen and nutrient supply, and metabolic microenvironment of human tumors: a review. Cancer Res 49: 6449-6465

Workman P, Twentyman P, Balkwill F, Balmain A, Chaplin D, Double J, Embleton J, Newell D, Raymond R, Stables J, Stephens T, Wallace I (1998) United Kingdom Co-ordinating Committee on Cancer Research (UKCCCR) Guidelines for the Welfare of Animals in Experimental Neoplasia (Second Edition). Br J Cancer 77: $1-10$

Wouters BG, Brown JM (1997) Cells at intermediate oxygen levels can be more important than the 'hypoxic fraction' in determining tumor response to fractionated radiotherapy. Radiat Res 147: 541-550

Wouters BG, Weppler SA, Koritzinsky M, Landuyt W, Nuyts S, Theys J, Chiu RK, Lambin P (2002) Hypoxia as a target for combined modality treatments. Eur I Cancer 38: 240 - 257

Yamaura H, Matsuzawa T (1979) Tumour regrowth after irradiation: an experimental approach. Int J Radiat Biol 35: $201-219$

Young WK, Vojnovic B, Wardman P (1996) Measurement of oxygen tension in tumours by time-resolved fluorescence. Br J Cancer 74(Suppl XXVII): S256-S259

Zölzer F, Streffer C (2002) Increased radiosensitivity with chronic hypoxia in four human tumor cell lines. Int J Radiat Oncol Biol Phys 54: 910-920 